\title{
Plague in Guinea Pigs and Its Prevention by Subunit Vaccines
}

\author{
Lauriane E. Quenee, ${ }^{* \dagger}$ Nancy Ciletti, ${ }^{, \dagger}$ \\ Bryan Berube, ${ }^{*}$ Thomas Krausz, ${ }^{\ddagger}$ Derek Elli, ${ }^{* \dagger}$ \\ Timothy Hermanas, ${ }^{\star \dagger}$ and Olaf Schneewind ${ }^{\star \dagger}$ \\ From the Departments of Microbiology* and Pathology, ${ }^{\ddagger}$ The \\ University of Chicago, Chicago; and the Howard Taylor Ricketts \\ Laboratory, ${ }^{\dagger}$ Argonne National Laboratory, Argonne, Illinois
}

Human pneumonic plague is a devastating and transmissible disease for which a Food and Drug Administration-approved vaccine is not available. Suitable animal models may be adopted as a surrogate for human plague to fulfill regulatory requirements for vaccine efficacy testing. To develop an alternative to pneumonic plague in nonhuman primates, we explored guinea pigs as a model system. On intranasal instillation of a fully virulent strain, Yersinia pestis C092, guinea pigs developed lethal lung infections with hemorrhagic necrosis, massive bacterial replication in the respiratory system, and blood-borne dissemination to other organ systems. Expression of the $\boldsymbol{Y}$. pestis F1 capsule was not required for the development of pulmonary infection; however, the capsule seemed to be important for the establishment of bubonic plague. The mean lethal dose (MLD) for pneumonic plague in guinea pigs was estimated to be 1000 colony-forming units. Immunization of guinea pigs with the recombinant forms of LcrV, a protein that resides at the tip of Yersinia type III secretion needles, or F1 capsule generated robust humoral immune responses. Whereas LcrV immunization resulted in partial protection against pneumonic plague challenge with 250 MLD Y. pestis CO92, immunization with recombinant F1 did not. rV10, a vaccine variant lacking LcrV residues 271-300, elicited protection against pneumonic plague, which seemed to be based on conformational antibodies directed against LcrV. (Am J Pathol 2011, 178:1689-1700; DOI: 10.1016/j.ajpath.2010.12.028)

Due to fulminant spread and high mortality, plague epidemics are thought to have killed more people worldwide than any other infectious disease. ${ }^{1,2}$ Several species of mammals, including rats, squirrels, mice, prairie dogs, and gerbils, represent animal reservoirs for the plague pathogen, ${ }^{3,4}$ which is transmitted to humans via flea bite, aerosol, or contact. ${ }^{5,6}$ Flea bite transmission limits Yersinia pestis replication initially to local lymph nodes with characteristic swellings (buboes) and disease symptoms that frequently progress to systemic spread of the pathogen and the lethal outcome of bubonic plague. ${ }^{7}$ Aerosol transmission of $Y$. pestis, whether during plague epidemics or deliberate dissemination, causes pneumonic plague, a disease with rapid fatality and few characteristic symptoms. ${ }^{8}$ Ubiquitous spread of zoonotic reservoirs with insect vectors for plague and the possibility of illegitimate use of $Y$. pestis as a weapon are public health concerns that could be addressed by the development of vaccines to protect humans against bubonic and pneumonic plague..$^{9,10}$

The ultimate goal of plague vaccine research is the development of safe products that generate protective immunity in humans but that cannot be defeated by naturally occurring $Y$. pestis strains or their mutant variants. ${ }^{11-13}$ Two subunit antigens, purified F1 pilin, ${ }^{14}$ ie, the recombinant form of capsular fraction 1 (Caf1), ${ }^{15}$ and $\mathrm{LcrV}^{16}$ a protein residing at the tip of type III needle complexes, ${ }^{17}$ are currently considered the only protective antigens for plague vaccines. ${ }^{18-21}$ The utility of these two antigens, either alone or in combined vaccine preparations, has been challenged. ${ }^{12}$ The Y. pestis variants lacking F1 capsule continue to cause lethal plague infections, at least in mice and nonhuman primates (NHPs). ${ }^{22,23}$ Furthermore, the ability of LcrV- or

Supported in part by the NIH/NIAID Challenge Award U01-AI070559 "LcrV Plague Vaccine with Altered Immune Modulatory Properties" (to O.S.).

The authors acknowledge membership within and support from the Region V Great Lakes Regional Center of Excellence in Biodefense and Emerging Infectious Diseases Consortium (NIH Award 1-U54-AI-057153 to O.S.)

Accepted for publication December 23, 2010.

L.E.Q., N.C., D.E., and O.S. hold a patent on rV10 for use as a plague vaccine.

Address reprint requests to Olaf Schneewind, M.D., Ph.D., Louis Block Professor \& Chair, Department of Microbiology, The University of Chicago, 920 E 58th St, Chicago, IL 60637. E-mail: oschnee@ bsd.uchicago.edu. 
F1-mediated immune responses in humans to generate protective immunity against pneumonic plague has not yet been demonstrated. ${ }^{21}$

The current incidence of plague is low, estimated to be approximately 4000 cases worldwide, and efficacy testing of plague vaccines may not be feasible with vaccine trials in human populations. ${ }^{6}$ Animal models of plague infection have been adopted as a surrogate for human plague and vaccine efficacy testing to fulfill the "Animal Rule," a government regulation enabling the Food and Drug Administration to license biodefense vaccines for diseases with low incidence (Code of Federal Regulations, Title 21, Volume 5, Part 314-Approval of New Drugs when Human Efficacy Studies Are Not Ethical or Feasible). Several plague models have been developed; mice, ${ }^{24}$ rats, ${ }^{25,26}$ and $\mathrm{NHPs}^{23,27}$ are, to date, the best characterized systems. Mouse and rat models have the advantages of low costs and large supplies of laboratory animals. Nevertheless, the murine respiratory tract and immune system differ significantly from those of humans. Because they are closely related to humans, NHPs are considered the most appropriate pneumonic plague model. Experiments with NHPs are, however, expensive. The limited availability of these animals restricts the size of test cohorts and affects the statistical interpretation of efficacy tests. Furthermore, NHP experiments are complicated by the variable genetic backgrounds, disease histories, and immune responses of these animals. We, therefore, sought to develop an alternative model under the "Animal Rule" and explored pneumonic plague in guinea pigs. ${ }^{28}$

Guinea pigs have been sporadically used to study plague infection. Initially, the animals were used as a reservoir species to grow and maintain virulent strains of Y. pestis. ${ }^{29}$ For the testing of whole-cell vaccines, guinea pigs were used as a model to study protection against bubonic plague. ${ }^{28}$ Earlier work reported that guinea pigs immunized with live-attenuated vaccine strains, eg, $Y$. pestis M23 $\left(\mathrm{F}^{-}{ }^{-}\right)^{30}$ and EV $(\Delta p g m),{ }^{31}$ develop protection against S.C. challenge with fully virulent plague isolates. ${ }^{28,32}$ When used for the testing of whole-cell-killed vaccines, the guinea pig model offered the same level of bubonic plague protection as did the mouse model. ${ }^{33}$ Two subunit vaccines, F1V fusion and $\mathrm{rLcrV}+\mathrm{rF} 1$, were tested in guinea pigs and generated protection against s.c. challenge with fully virulent $Y$. pestis. ${ }^{34,35}$ The mean lethal dose (MLD) and histopathologic attributes of bubonic plague in guinea pigs have, however, not yet been characterized. ${ }^{34}$ Furthermore, although previous work demonstrated guinea pig susceptibility to pneumonic plague, ${ }^{36}$ the efficacy of subunit vaccines in the guinea pig model system is not yet known. ${ }^{35}$

\section{Materials and Methods}

\section{Bacterial Strains and Plasmids}

The fully virulent $Y$. pestis strain $C O 92^{37,38}$ and the variants CO92 $\Delta \mathrm{F} 1^{20}$ and $C A C 1^{39}$ have been previously described. The $\Delta \mathrm{F} 1$ variant of $Y$. pestis CO92 carries a deletion of the caf1 gene, which encodes the F1 (Caf1) pilin subunit of plague bacteria. ${ }^{20}$ The $\mathrm{CAC} 1$ strain harbors an insertion of the IS1541 element in the caf1A gene, which abrogates F1 pilus assembly but not pilin expression. ${ }^{39}$

\section{Purification of rLcrV, rV10, and rF1}

The pET-16b (Merck KGaA, Darmstadt, Germany) expression vectors ${ }^{40}$ for rLcrV and $\mathrm{rV} 10$ have been described previously. ${ }^{41}$ The $Y$. pestis KIM coding sequence of caf $^{42}$ was PCR amplified with primers specifying abutted Ndel and BamHI restriction sites. Amplified DNA fragments were subcloned into the expression vector pET$15 \mathrm{~b}$ and digested with $\mathrm{Ndel}$ and $\mathrm{BamHI}$, to yield prF1. Escherichia coli BL21(DE3) carrying the expression vectors were grown overnight at $37^{\circ} \mathrm{C}$ in Luria-Bertani medium with $100 \mu \mathrm{g} / \mathrm{mL}$ of ampicillin. Bacteria were diluted in fresh medium and were grown to $\mathrm{OD}_{600} 0.5$. $\mathrm{T7}$ polymerase was induced with $1 \mathrm{mmol} / \mathrm{L}$ isopropyl-1-thiol-Dgalactopyranoside, and bacterial growth was continued for 3 hours at $37^{\circ} \mathrm{C}$. Bacteria were sedimented by centrifugation at $10,000 \times g$ for 15 minutes, and $E$. coli cells from 500-mL culture were disrupted twice in a French pressure cell at $14,000 \mathrm{psi}$ in $20 \mathrm{~mL}$ of $50 \mathrm{mmo} / \mathrm{L}$ Tris- $\mathrm{HCl}(\mathrm{pH}$ 7.5) $-150 \mathrm{mmol} / \mathrm{L} \mathrm{NaCl}$ (column buffer). Cleared lysates were applied to a nickel nitrilotriacetic acid column (1-mL bed volume) pre-equilibrated with $20 \mathrm{~mL}$ of column buffer. The column was washed with 20 volumes of the same buffer, followed by a second washing with 20 volumes of column buffer containing $20 \mathrm{mmol} / \mathrm{L}$ imidazole. Protein was eluted in $50 \mathrm{mmol} / \mathrm{L}$ Tris- $\mathrm{HCl}(\mathrm{pH} 7.5)-150 \mathrm{mmol} / \mathrm{L}$ $\mathrm{NaCl}$ with $250 \mathrm{mmol} / \mathrm{L}$ imidazole. Proteins were extracted with 1\% Triton X-114 (Sigma-Aldrich, St. Louis, MO) to remove endotoxin and detergent removed by chromatography on a HiTrap desalting column (GE Healthcare, Bio-Science AB, Uppsala, Sweden); proteins were eluted in PBS. Lipopolysaccharide contamination of vaccine antigens was assayed with Limulus amebocyte lysate (QCL1000; Cambrex Corp., East Rutherford, NJ). ${ }^{43}$ Protein concentrations were determined using the bicinchoninic acid assay (Pierce Biotechnology, Rockford, IL) or by measuring absorption at $280 \mathrm{~nm}$. Proteins were flash frozen with dry ice and ethanol and were stored at $-80^{\circ} \mathrm{C}$ until further use.

\section{Immunizations}

Female Hartley guinea pigs weighing $250 \mathrm{~g}$ (Charles River Laboratories International Inc., Wilmington, MA) were immunized twice by i.m. injection into the hind leg with 0.1 -mL aliquots of $50 \mu \mathrm{g}$ of recombinant rLcrV, rV10, or rF1 adsorbed to $25 \%$ aluminum hydroxide (Alhydrogel; Brenntag Biosector, Frederikssund, Denmark) on days 0 and 21. Blood was collected on day 42 to measure serum antibody titers before plague challenge. For antibody detection, the levels of serum IgG reactive with specific antigens were determined using a custom enzyme-linked immunosorbent assay (ELISA) designed by the Great Lakes Regional Center of Excellence Animal Research and Immunology Core at The University of Chicago. ${ }^{24}$ Briefly, serum samples representative of the immunization group were aliquoted on microtiter plates precoated 
with histidine-tagged rF1, rLcrV, or rV10 antigens $(1 \mu \mathrm{g} /$ $\mathrm{mL}$ ). Binding of serum antibody was detected with secondary antibodies against guinea pig Ig. Peroxidase AffiniPure Goat Anti-Guinea Pig IgG $(\mathrm{H}+\mathrm{L})$ from Jackson ImmunoResearch Laboratories Inc., West Grove, PA. Additional experiments were performed to examine the contribution of antihistidine antibodies to mean IgG titers. Findings revealed that the level of specific antihistidine antibodies was negligible in the sera of guinea pigs immunized with rF1, rLcrV, and rV10 (data not shown). Statistical analysis of antibody levels as a pairwise comparison used the $t$-test.

\section{Plague Challenge Experiments}

For the bubonic plague model, guinea pigs were challenged by s.c. injection with $0.1-\mathrm{mL}$ aliquots of increasing doses of $Y$. pestis CO92. For this experiment, $Y$. pestis C092 was grown in heart infusion broth at $26^{\circ} \mathrm{C}$ overnight. Growth of $Y$. pestis at $26^{\circ} \mathrm{C}$ is thought to mimic the ambient temperature in infected fleas before transmission of bubonic plague. ${ }^{44}$ Plague bacilli were washed and diluted in sterile PBS to the required concentration. Guinea pigs were infected by s.c. injection with bacterial suspensions and were observed for morbidity, mortality, or recovery for 21 days. For the pneumonic plague model, guinea pigs were anesthetized with a cocktail of $30 \mathrm{mg} / \mathrm{mL}$ of ketamine (Ketaved; Vedco Inc., St. Joseph, $\mathrm{MO}$ ) and $3 \mathrm{mg} / \mathrm{mL}$ of xylazine (Sigma-Aldrich) (administered i.p.) and challenged by intranasal inoculation with $50 \mu \mathrm{L}$ of increasing doses of $Y$. pestis CO92. For this experiment, $Y$. pestis CO92 was grown in heart infusion broth supplemented with $2.5 \mathrm{mmol} / \mathrm{L}$ calcium at $37^{\circ} \mathrm{C}$ overnight, conditions that mimic the temperature during man-to-man transmission of pneumonic plague. ${ }^{44}$ Plague bacteria were washed and diluted in sterile PBS at the required concentration. Guinea pigs were observed for morbidity, mortality, or recovery for 14 days. Challenge after immunization was performed as described previously herein 21 days after the second injection of vaccines. For passive transfer experiments in mice, $200 \mu \mathrm{L}$ of guinea pig serum was injected into the peritoneal cavity of 6- to 8-week-old naive BALB/c mice 1 hour before S.C. challenge with 20 colony-forming units (CFU) of $Y$. pestis CO92 or CAC1.

Analysis of the statistical significance of mortality studies was performed using Fisher's exact test. Statistical significance of mean time to death was calculated using the two-tailed $t$-test. All animal and plague experiments were performed in accordance with institutional guidelines following experimental protocol review and approval by the Institutional Biosafety Committee, the Select Agent Committee, and the Institutional Animal Care and Use Committee at The University of Chicago.

\section{CAC1 Variant Characterization}

Presence of the IS1541 element in the caf1A gene was determined by PCR. caf1A was amplified using a DNA polymerase (Z-Taq; Takara Bio Inc., Otsu, Japan) and the following primers: 5'Caf1A-Sphl (5'-TAGCATGCATGAG-
GTATTCAAAGCTGTTCC-3') and 3'Caf1A-Sacl (5'TAGAGCTCTCAGTTATTTAAGATGCAGG-3'). The PCR products were separated on $1 \%$ agarose to determine caf1A PCR product sizes in C092, CAC1 (caf1A::IS1541), and various isolates. Presence of $\mathrm{F} 1$ pilin on the surface of bacteria was assessed by fractionation of $Y$. pestis grown overnight in heart infusion broth supplemented with $2.5 \mathrm{mmol} / \mathrm{L}$ calcium chloride at $37^{\circ} \mathrm{C}$. Bacterial sediment (pellet) and culture supernatant were separated by centrifugation at $13,000 \times g$ for 5 minutes. Protein present in the supernatant and pellet fractions were TCAprecipitated and suspended in sample buffer for SDSpolyacrylamide gel electrophoresis. Proteins from both fractions were separated by $15 \%$ SDS- polyacrylamide gel electrophoresis and were electrotransferred onto polyvinylidene difluoride membrane before detection with F1-specific rabbit polyclonal antibodies.

\section{NHP Plague Challenge}

Using head-only inhalation, cynomolgus macaques were challenged at Lovelace Respiratory Research Institute (Albuquerque, NM) with a dose of $400 \mathrm{CFU}$ of $Y$. pestis CO92 or CAC1, as previously described. ${ }^{45}$ For this procedure, cynomolgus macaques were fasted for 12 to 18 hours (overnight) before exposure to minimize the likelihood of vomiting in response to anesthesia and the possible sequelae of aspiration pneumonia during the procedure. Animals were anesthetized with 2 to $6 \mathrm{mg} / \mathrm{kg}$ of Telazol (Fort Dodge Animal Health, Fort Dodge, IA) approximately 15 minutes before aerosol exposure. For this experiment, Y. pestis strains CO92 or CAC1 were grown for 72 hours at $26^{\circ} \mathrm{C}$, washed, suspended in sterile $1 \%$ peptone, diluted in brain heart infusion broth, and aerosolized with a Collison nebulizer (MRE-3 jet; BGI Inc., Waltham, MA). The aerosol was sampled directly using an all-glass impinger (Ace Glass Inc., Vineland, NJ), and samples were drawn from the head-only exposure chamber, downstream from the macaque's nostrils. The bacterial concentrations and the purity of the challenge preparation were determined by quantitative bacterial culture of aerosol samples and by assessing colony morphologic features on tryptic soy and Congo red agar. The target particle size was 1 to $3 \mu \mathrm{m}$, as determined using an Aerodynamic Particle Sizer spectrometer (model 3321; TSI Inc., Shoreview, MN). Inhaled aerosol doses were determined using plethysmography (Buxco, Wilmington, $\mathrm{NC}$ ). Animal respiratory frequency, tidal volume, and minute volume were recorded during exposure, and the targeted inhaled volume for each exposure was $3.5 \mathrm{~L}$. The concentrations of $Y$. pestis in nebulizer suspensions were established before aerosol delivery so that a known number of bacteria per minute could be delivered. The NHP protocol and any amendment(s) or procedures involving the care and use of animals in this study were reviewed and approved by Lovelace Respiratory Research Institute's Institutional Animal Care and Use Committee before the study was conducted. During the study, the care and use of animals was in accordance with the guidelines of the US National Research Council. The moribund an- 
imals were euthanized and necropsied, and their lungs were analyzed using histopathologic methods.

\section{Histopathologic Analysis}

Animal tissues obtained during necropsy were fixed in $10 \%$ neutral buffered formalin and were embedded in paraffin. Blocks were sectioned at $5 \mu \mathrm{m}$ and were stained with H\&E before microscopy and image analysis.

\section{Results}

\section{Pneumonic Plague in NHPs after Infection with Wild-Type or F1 Mutant Y. pestis}

Previous work reported lethal pneumonic plague disease in cynomolgus macaques (Macaca fascicularis) after aerosol infections with $Y$. pestis CO92. ${ }^{27,45}$ Nonhuman primates are also known to succumb to pneumonic plague after aerosol challenge with F1 mutant strains. ${ }^{36}$ We compared the histopathologic findings of pneumonic plague caused by $\mathrm{Y}$. pestis CO92, an $\mathrm{F}^{+}$clinical isolate, with that precipitated by its derivative, $Y$. pestis $\mathrm{CAC} 1\left(\mathrm{~F} 1^{-}\right)$, a strain that carries an IS1541 insertion in the caf1A structural gene for the outer membrane usher and, therefore, cannot assemble F1 pili. ${ }^{39}$ Lung tissues from cynomolgus macaques that died of pneumonic plague after infection with 400 CFUs of either $Y$. pestis CO92 or CAC1 were stained with H\&E (Figure 1). ${ }^{45}$ Lung tissue from a macaque that died of $Y$. pestis CO92 infection revealed acute pneumonia. Alveolar lumina were filled with edem-

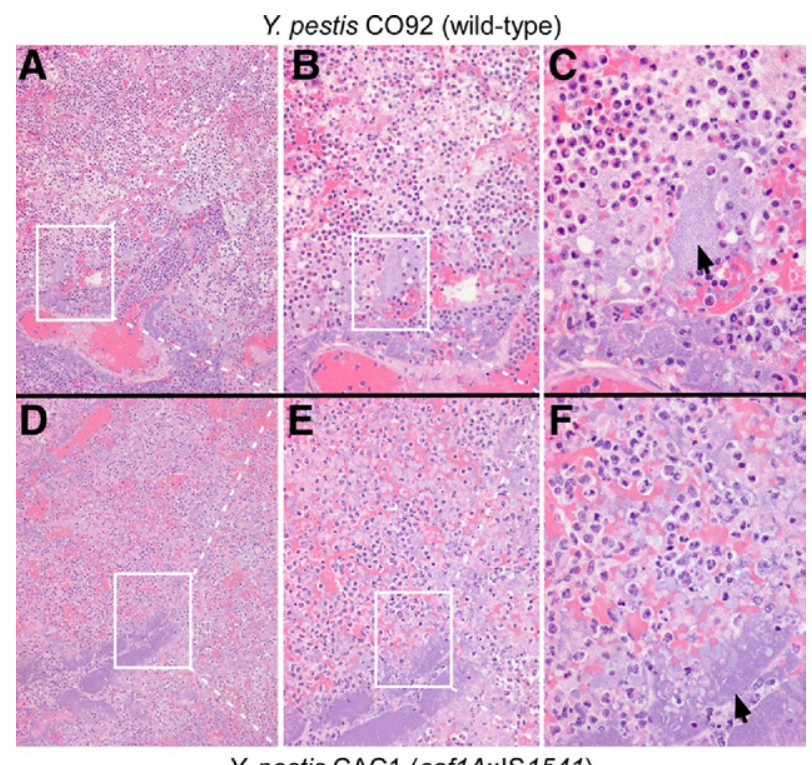

Y. pestis CAC1 (caf1A::IS1541)

Figure 1. Pneumonic plague in NHPs caused by wild-type and caf1 variant $Y$. pestis. The lungs of cynomolgus macaques that died of aerosol infection with 400 CFU of either $Y$. pestis CO92 (A-C) or Y. pestis CAC1 (caf1A::IS 1541) (D-F) were removed during necropsy. Lung lobes were perfused via bronchi with $10 \%$ formalin, embedded in paraffin, thin sectioned, and stained with H\&E. Arrows indicate bacterial colonies. The boxes in panels $\mathbf{A}$ and $\mathbf{D}$ identify the areas of enlargement in panels $\mathbf{B}$ and $\mathbf{E}$. The boxes in panels $\mathbf{B}$ and $\mathbf{E}$ identify the areas of enlargement in panels $\mathbf{C}$ and $\mathbf{F}$. Original magnification: $\times 100(\mathbf{A}$ and $\mathbf{D}) ; \times 200(\mathbf{B}$ and $\mathbf{E}) ; \times 400(\mathbf{C}$ and $\mathbf{F})$. atous fluid, fibrin filaments, numerous neutrophils, monocytes, and macrophages (Figure 1). Alveolar macrophages occasionally contained necrotic cellular debris and, to a lesser extent, bacteria. Large aggregates of bacteria were distributed in interstitial spaces and within alveoli. Lung parenchyma displayed multifocal, coalescing areas of necrosis obliterating the physiologic lung architecture. Multiple abscesses were characterized by central foci of lytic necrosis surrounded by degenerate neutrophils interspersed with bacteria entangled in fibrin and erythrocyte deposits (Figure 1). Similar histopathologic findings were observed in the lung tissues of a cynomolgus macaque that had died of aerosol infection with 400 CFU of $Y$. pestis CAC1 (Figure 1). These findings are in agreement with the hypothesis that the Caf1 capsule ( $\mathrm{F} 1$ pili) is not required for the development of pneumonic plague in NHPs. Furthermore, histopathologic observations in NHPs serve as a reference point for the development of a guinea pig model for pneumonic plague (see later herein).

\section{Clinical Manifestations of Pneumonic Plague in Guinea Pigs}

Guinea pigs (cohorts of eight animals) were inoculated by intranasal instillation with increasing doses of $Y$. pestis CO92, ranging from $1.5 \times 10^{3}$ to $3.5 \times 10^{5} \mathrm{CFU}$ (Figure 2A). Within 24 hours of challenge with more than $1.5 \times 10^{3}$ CFU, animals presented with piloerection around the neck and up to $3 \%$ loss of body weight. The disease progressed rapidly, and animals died 3 to 4 days after challenge, depending on the size of the infectious dose (Figure 2A). Clinical signs were consistent with pulmonary disease-labored breathing, gasping, epistaxis, and ocular serous discharge. Guinea pigs are obligate nose breathers, and some of the infected animals developed aerophagia with an inflated abdomen. On day 3 or 4 , when severe pneumonia was recorded, changes in body temperature or weight between infected and uninfected animals were not significantly different (data not shown).

At an infectious dose of $1.5 \times 10^{3} \mathrm{CFU}$, early signs of disease appeared 5 to 7 days after infection. Animals that died of infection displayed a disease progression comparable with that described for the higher challenge dose (see previously herein); death occurred 9 to 10 days after infection (Figure 2A). On intranasal instillation with $Y$. pestis CO92, an MLD of $1000 \mathrm{CFU}$ was calculated for guinea pigs from data gathered in two independent experimental trials. $^{46}$

\section{Plague Bacteria Disseminate from the Lung to the Spleen of Infected Guinea Pigs}

Guinea pigs (cohorts of five animals) were inoculated by intranasal instillation with $3 \times 10^{4}$ CFU (30 MLD) of $Y$. pestis CO92 and were sacrificed at variable time points after infection (Figure 2B). One hour after infection, $10^{4}$ to $10^{5} \mathrm{CFU}$ were recovered from the lungs of infected animals (Figure 2B). At this early stage and even 24 hours after infection, plague bacteria could not be isolated from 

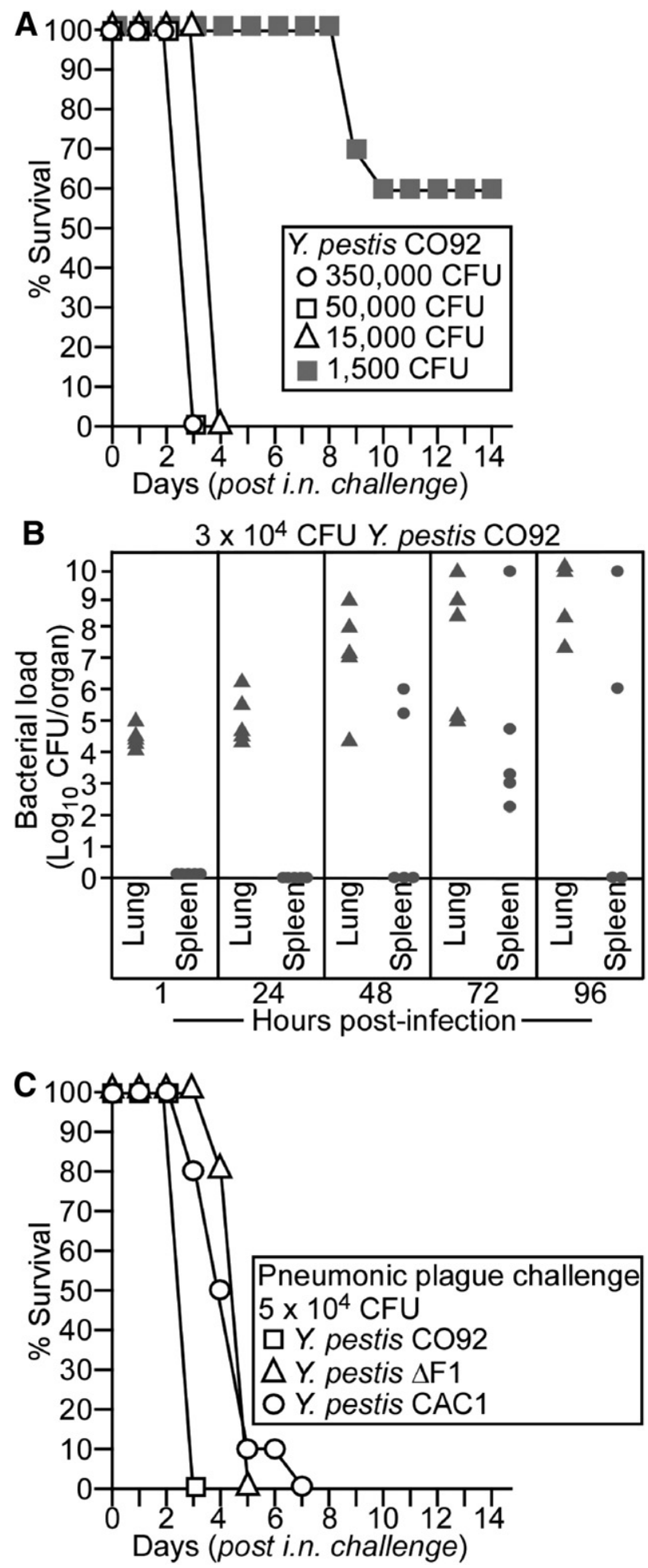

Figure 2. Wild-type and caf1 variant $Y$. pestis cause pneumonic plague in guinea pigs. A: Hartley guinea pigs $(n=8)$ were inoculated by intranasal (i.n.) instillation with increasing doses of $Y$. pestis CO92. Guinea pigs were monitored for disease progression and survival for 14 days. B: Hartley guinea pigs were inoculated by i.n. instillation with $3 \times 10^{4}$ CFU of $Y$. pestis CO92. At 1, 24, 48, 72, and 96 hours after infection, guinea pigs (cohorts of five animals) were sacrificed. Lung and spleen were removed during necropsy, and tissue homogenates of these organs were spread on Congo red heart infusion agar and incubated for $Y$. pestis colony enumeration. C: Hartley guinea pigs (cohorts of six animals) were infected by i.n. instillation with $5 \times$ $10^{4}$ CFU of $Y$. pestis CO92, CO92 $\Delta \mathrm{F} 1$, or $Y$. pestis CAC1 (caf1A::IS1541) Guinea pigs were monitored for disease progression and survival for 14 days. the spleens of infected animals (Figure 2B). Massive replication of plague bacteria occurred in lung tissues within 48 to 72 hours of infection, and the development of pneumonia was frequently associated with dissemination of $Y$. pestis C092 to spleen tissues. By 96 hours after infection, one infected guinea pig had died and was not analyzed further. The remaining animals revealed a high load of plague bacteria in lung tissue (up to $1 \times 10^{10} \mathrm{CFU}$ ). A high burden of plague bacteria in the spleen was observed in two of four animals (Figure $2 \mathrm{~B}$ ).

\section{Y. pestis F1 Variants Cause Pneumonic Plague in Guinea Pigs}

Friedlander and colleagues ${ }^{36}$ reported that the MLD for pneumonic plague in guinea pigs was 1 log higher for Y. pestis Java $9\left(\mathrm{~F}^{-}\right)$than for $Y$. pestis $\mathrm{CO} 2\left(\mathrm{~F}^{+}\right)$. Because the two strains do not represent a pair of wild type and its isogenic F1 variant, the data cannot assess the relative contribution of the $\mathrm{F} 1$ capsule to pneumonic plague disease. Nevertheless, most plague vaccines are based on protection elicited by LcrV and F1 subunits. We, therefore, asked whether isogenic plague variants defective for Caf1 capsule expression reveal a contribution of F1 pili to the pathogenesis of pneumonic plague. Guinea pigs (cohorts of six animals) were inoculated by intranasal instillation with $5 \times 10^{4} \mathrm{CFU}$ of $Y$. pestis CO92, C092 $\Delta \mathrm{F} 1$ (an engineered isogenic $\mathrm{F}^{-}{ }^{-}$strain), ${ }^{20}$ or $Y$. pestis CAC1 (a caf1A::IS1541 escape variant isolated from F1-immunized mice). ${ }^{39}$ All the animals died of infection within 7 days (Figure $2 \mathrm{C}$ ). Thus, similar to pneumonic plague in mice, F1 variants displayed a similar lethal dose in guinea pigs as the parent strain C092. ${ }^{39}$ Progression of pneumonic plague seemed somewhat reduced for the $\mathrm{F}^{-}$strains (Figure 2C). The mean $\pm \mathrm{SD}$ time to death for $Y$. pestis CO92 infection was $3 \pm 0$ days and for C092 $\Delta \mathrm{F} 1$ was $4.83 \pm 0.37$ days $(P=2.1 \times$ $\left.10^{-5}\right)$. There was no significant difference comparing the mean $\pm \mathrm{SD}$ time to death of the two $\mathrm{F}^{-}{ }^{-}$variants, CO92 $\Delta \mathrm{F} 1$ and $\mathrm{CAC} 1(4.83 \pm 0.37$ and $4.6 \pm 1.24$ days, respectively; $P=0.78)$.

The experiment in Figure $2 \mathrm{C}$ was repeated with two animals per group. On day 3 , all the animals were subjected to necropsy, and lung tissue was removed. Samples were formalin fixed, embedded in paraffin, thin sectioned, and stained with H\&E (Figure 3). Histopathologic examination of infected animals revealed bacterial pneumonia. Compared with uninfected animals (Figure 3, A, E, and I), large numbers of polymorphonuclear leukocytes (neutrophils) and macrophages were detected in the lumen of alveoli of $Y$. pestis CO92-infected guinea pigs (Figure 3, B, F, and J). Foci of cell necrosis surrounded bacterial colonies in infected lung tissue (Figure 3, B, F, and J). Hemorrhage and perivascular edema were observed in the lungs, similar to the histopathologic findings of pneumonic plague in NHPs (Figure 1) and in humans. ${ }^{8}$ At the same time point, the lungs of guinea pigs infected with $\mathrm{F}^{-}{ }^{-}$variants $(\triangle \mathrm{F} 1$ or $\mathrm{CAC} 1)$ displayed similar stages of disease progression (Figure 3, C, D, G, H, K, and L). Portions of the lungs still harbored alveoli with a normal 


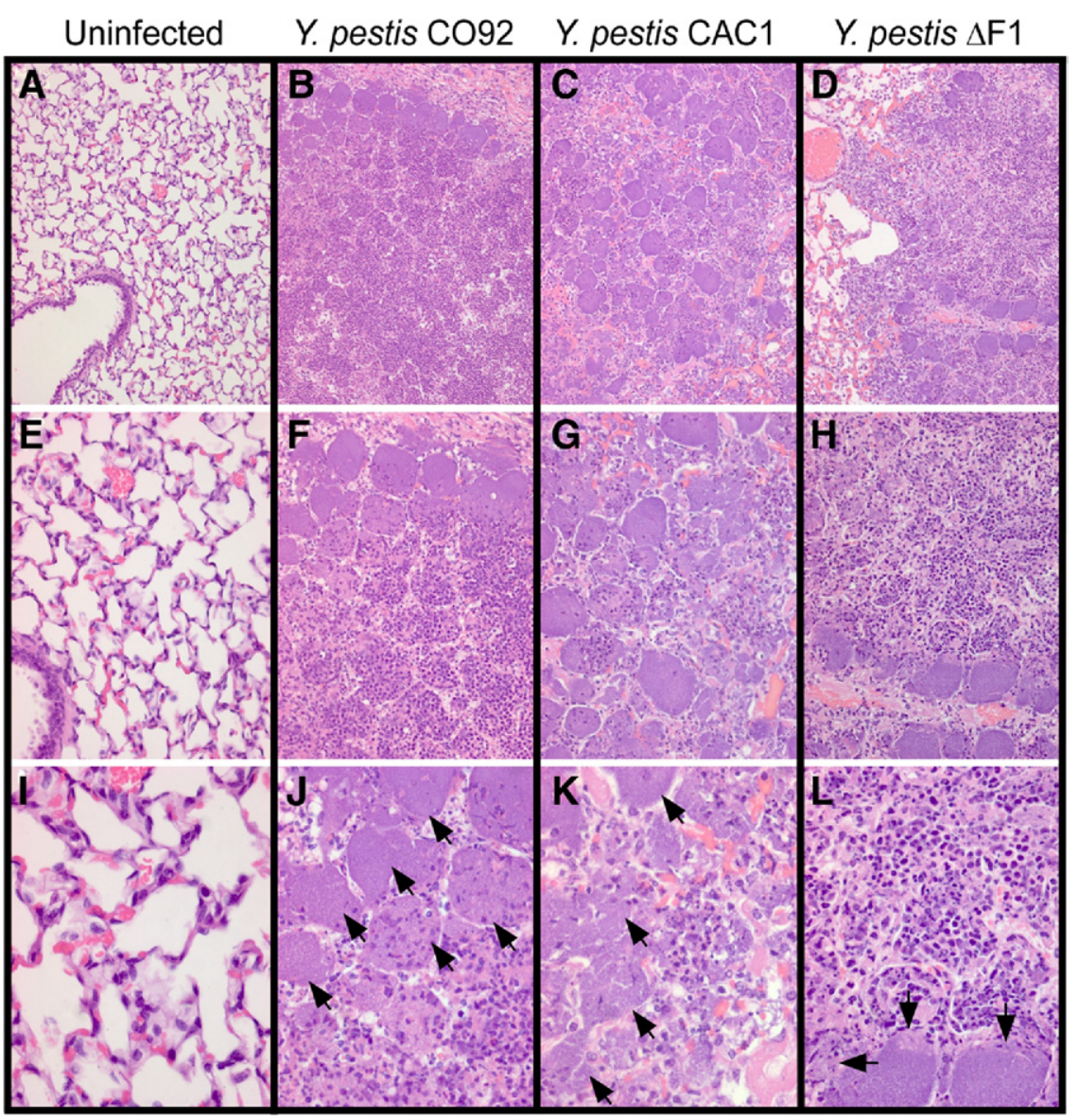

Figure 3. Infection with $Y$. pestis induced pneumonia in the lungs of guinea pigs. Lungs from guinea pigs infected with $Y$. pestis $\mathrm{CO} 92(\mathbf{B}, \mathbf{F}$, and $\mathbf{J})$ or its isogenic variants $\mathrm{CAC} 1(\mathbf{C}, \mathbf{G}$, and $\mathbf{K})$ and $\Delta \mathrm{F} 1(\mathbf{D}, \mathbf{H}$, and $\mathbf{L})$ were removed during necropsy, perfused via the trachea with $10 \%$ formalin, embedded in paraffin, thin sectioned, and stained with H\&E. Arrows identify bacterial colonies. As a control, the left panels display the lung tissue of an uninfected guinea pig $(\mathbf{A}, \mathbf{E}$, and $\mathbf{I}$ ). Images in the top row (A-D) were enlarged and are displayed in the middle row $(\mathbf{E}-\mathbf{H})$ and images in the middle row $(\mathbf{E}-\mathbf{H})$ were enlarged and are displayed in the bottom row $(\mathbf{I}-\mathbf{L})$ to reveal histopathologic features of pneumonic plague in guinea pigs. Original magnification: $\times 100(\mathbf{A}-\mathbf{D})$ $\times 200(\mathbf{E}-\mathbf{H}) ; \times 400(\mathbf{I}-\mathbf{L})$.

structure, although infiltration of inflammatory cells with distended alveolar epithelial walls containing polymorphonuclear leukocytes were also detectable. Foci of necrotic cells were detected in bacterial colonies. At higher magnification $(\times 400)$, pneumonic plague lesions of animals infected with wild-type bacteria were comparable with those caused by $\mathrm{F}^{-}{ }^{-}$variants (Figure 3, J, K, and L). Taken together, these data suggest that the observed differences in mean time to death could be due to the somewhat slower progression of inflammatory lesions in lung tissues. Nevertheless, guinea pigs infected with $\mathrm{F}^{-}$ and $\mathrm{F} 1^{+}$strains of $Y$. pestis developed pneumonic plague disease. $\mathrm{F}^{-}$and $\mathrm{F}^{+}$strains displayed a similar MLD or bacterial burden in infected lungs.

\section{Bubonic Plague}

Guinea pigs (cohorts of six animals) were infected by s.c. injection into the inguinal fold with increasing doses of $Y$. pestis CO92 ranging from 7 to $2.1 \times 10^{5} \mathrm{CFU}$ (Figure 4A). At the highest infectious dose, clinical signs appeared 2 days after infection. Animals presented with piloerection around the neck and up to $10 \%$ weight loss; however, body temperatures were maintained at the preinfection baseline level (data not shown). Disease progression was associated with up to $15 \%$ weight loss by day 5 or 6 . An s.c. nodule developed at the injection site that was firm on palpation and occasionally caused mild limping. By days 8 to 14, limping worsened, weight loss reached $20 \%$, and disease progressed toward a lethal outcome, which was associated with a $2^{\circ} \mathrm{C}$ to $6^{\circ} \mathrm{C}$ drop in body temperature (data not shown). Animals appeared quiet and unresponsive and sometimes displayed a dried ocular discharge or closed eyes.

When infected with medium challenge doses (30 or 785 CFU), animals displayed slight piloerection on days 6 and 7 , with no significant weight loss or temperature change. Disease progression was very slow, and average weight loss on days 7 to 16 was less than 15\% (data not shown). During that time, animals developed buboes near the site of injection (inguinal fold). Animals that survived the infection regained their body weight by days 14 to 16 . Buboes resolved slowly over time and could not be palpated at the end of the observation period (21 days). For nonrecovering animals, the disease course was comparable with signs described for challenges with a high infectious dose; death occurred 9 to 16 days after challenge.

When infected with a sublethal dose (7 CFU), the weight of animals started to increase on days 7 and 8 . A small s.c. nodule was detected near the injection site; however, these lesions did not affect the mobility of animals. Although disease progression and the severity of the signs seemed to be dose dependent, guinea pigs were not uniformly susceptible to a lethal outcome of s.c. infection with $Y$. pestis CO92. For example, a dose of 30 CFU euthanized all the animals in a cohort (six guinea 
A

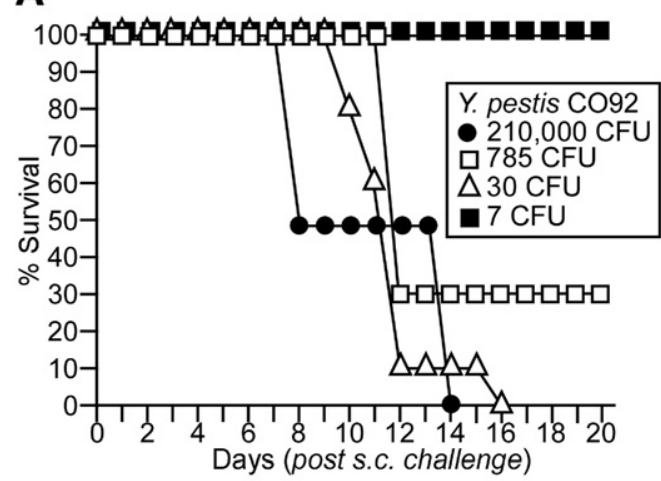

B

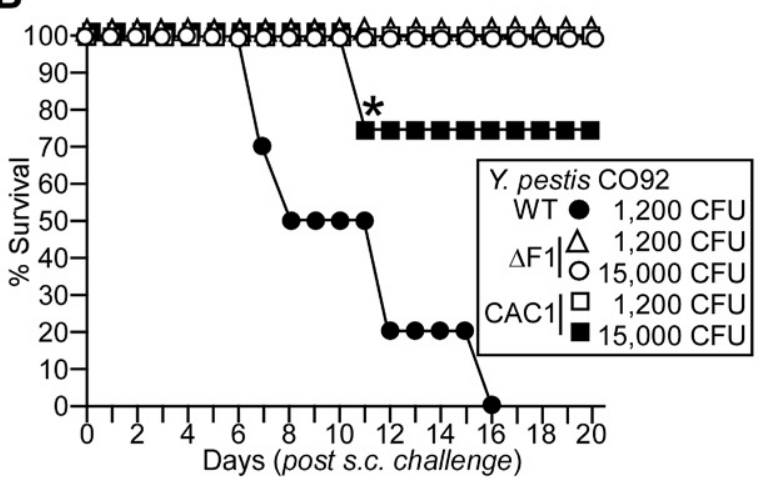

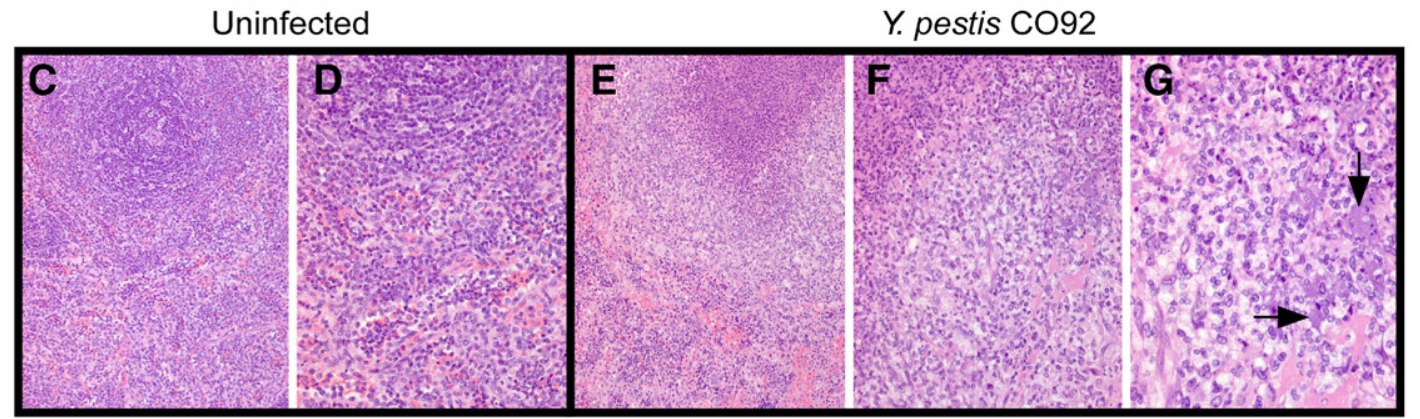

Figure 4. Subcutaneous infection with wild-type $Y$. pestis causes bubonic plague in guinea pigs. A: Hartley guinea pigs (cohorts of eight animals) were inoculated by s.c. injection with increasing doses of $Y$. pestis CO92. Guinea pigs were monitored for disease progression and survival for 21 days. B: Guinea pigs (cohorts of six animals) were inoculated by s.c. injection with $Y$. pestis strains CO92 (wild type), CO92 $\Delta$ F1, or CAC1 (caf1A::IS1541). Guinea pigs were monitored for disease progression and survival for 21 days. On day 11, one of the $Y$. pestis CAC1-infected animals died of plague infection (asterisk). The animal was necropsied and analyzed for the pathologic features of plague disease (see Figure 5). Spleens from uninfected guinea pigs $(\mathbf{C}$ and $\mathbf{D})$ and animals challenged with $Y$. pestis CO92 (E-G) were removed during necropsy, treated with $10 \%$ formalin, thin sectioned, and stained with H\&E. Arrows identify bacterial colonies. Original magnification: $\times 100(\mathbf{C}$ and $\mathbf{E}) ; \times 200(\mathbf{D}$ and $\mathbf{F}) ; \times 400(\mathbf{G})$

pigs), whereas two animals challenged with 785 CFU survived bubonic plague disease (Figure 4A).

For animals susceptible to bubonic plague infection, massive bacterial replication was observed in the lymph node adjacent to the injection site. The spleen and liver were infected with plague bacteria, which reached a load of up to $1 \times 10^{10} \mathrm{CFU}$ per gram of tissue at the time of death (data not shown). Gross examination at the injection site revealed the formation of a solid bubo often accompanied by necrosis of the adjacent muscle. The spleen and liver exhibited white, solid granular formations ( $\leq 2 \mathrm{~mm}$ in diameter; data not shown). Histopathologic analysis of spleens from $Y$. pestis CO92-infected guinea pigs revealed granulomatous lesions (Figure 4, E, F, and $\mathrm{G})$. Spleens exhibited a reduced white pulp and foci of necrosis surrounded by histiocytic reaction (Figure 4, E, $F$, and $G$ ). Despite granuloma formation, infections were not contained, and bacterial colonies were also detected at the periphery of these lesions. It seems plausible that the slow disease progression of bubonic plague is the result of granulomatous responses that, at least in part, contain the invading pathogen.

\section{Virulence of $Y$. pestis $F 1$ Variants during Bubonic Plague}

Guinea pigs (cohorts of six animals) were inoculated by s.c. injection with 1200 or 15,000 CFU of $Y$. pestis C092,
$\Delta \mathrm{F} 1$ or $\mathrm{CAC1}$. All animals infected with the wild-type parent strain died of infection within 16 days (Figure 4B), whereas all animals infected with the $\Delta \mathrm{F} 1$ variant survived the infection $(P=0.007)$. During the course of bubonic plague, four of six guinea pigs infected with 15,000 CFU of CAC1 presented with mild clinical signs (slight piloerection and inguinal lump). Three animals recovered and regained their body weight, and one animal exhibited respiratory distress and died of infection on day 11 (Figure 4B). The survival difference between the two F1 mutant strains was not significant $(P=0.49)$. Taken together, these results suggest that unlike during the pathogenesis of lung infections, the expression of $\mathrm{F} 1$ capsule by $Y$. pestis is an important contributor to the development of bubonic plague in guinea pigs.

\section{Secondary Pneumonic Plague in Guinea Pigs}

The spleen, liver, and lungs from the Y. pestis CACinfected guinea pig that died on day 11 after infection were subjected to histopathologic analysis (Figure 5). Splenic lesions resembled those observed in animals infected with the parent strain $Y$. pestis C092, with necrotic areas surrounded by histiocytic reaction (Figure 5, C and F). Similar lesions were also observed in the liver (Figure 5, D and G). Histopathologic analysis of lung tissue revealed secondary plague-induced pneumonia with massive inflammatory infiltration and 

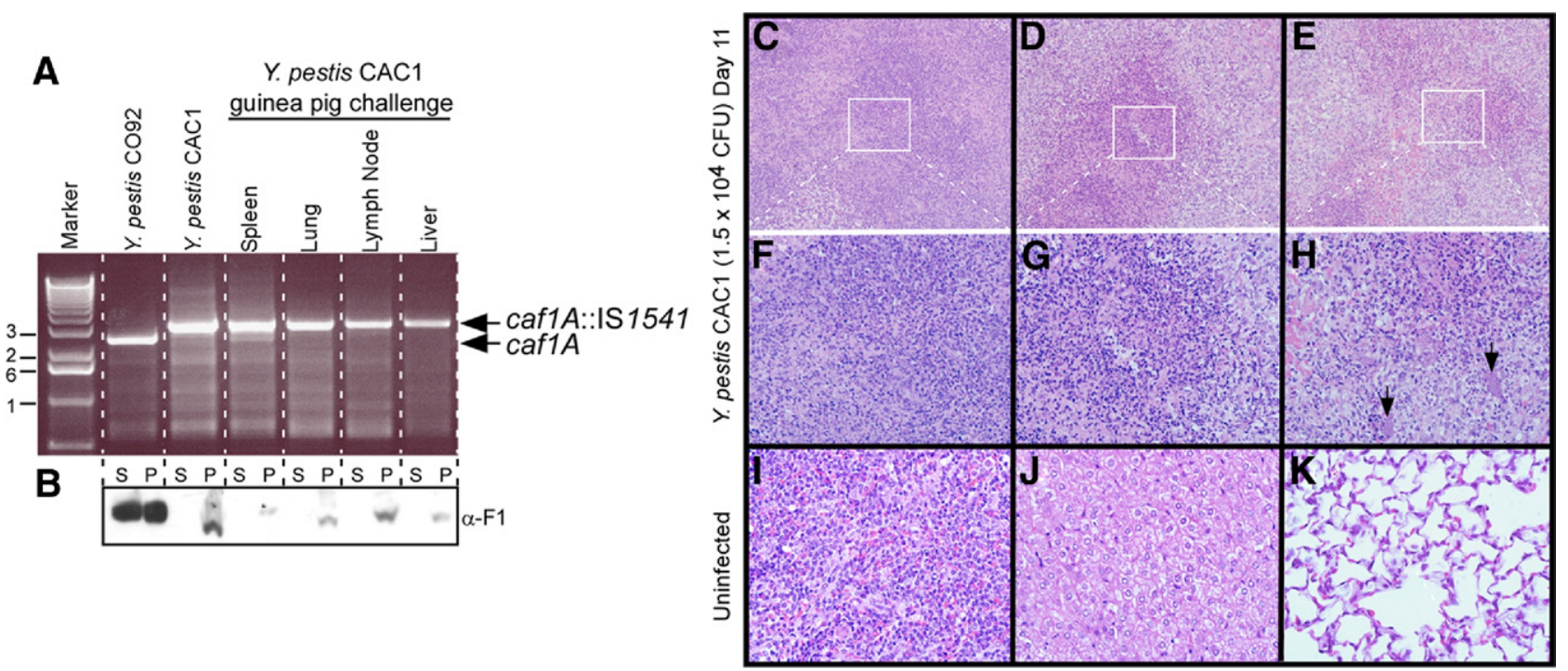

Figure 5. The $Y$. pestis caf1A::IS 1541 variant, strain CAC1, can cause bubonic plague in guinea pigs without reverting to an $\mathrm{F} 1^{+}$phenotype. A: Genomic DNA isolated from $Y$. pestis $\mathrm{CO} 22$ (wild type), $Y$. pestis $\mathrm{CAC1}$, or plague bacteria that were isolated from spleen, lung, lymph node, or liver tissues of a guinea pig that died of s.c. challenge with the CAC1 strain (asterisk in Figure 4B) was examined by PCR with oligonucleotide primers specific for the caf1A gene of pFRA. Arrows denote the mobility of PCR amplification products specific for caf1A or caf1A::IS1541. The 1-kb DNA ladder (Promega Corp, Madison, WI) was used as a calibration standard (marker). B: $Y$. pestis broth cultures from the same strains as described in $\mathbf{A}$ were centrifuged to separate proteins secreted into the culture supernatant (S) from the bacterial sediment (P) and analyzed by immunoblotting using polyclonal rabbit sera with antibodies specific for $\mathrm{rF1}$ ( $\alpha$-F1). C-K: Spleen, liver, and lung tissues of guinea pigs were removed during necropsy, fixed in formalin, thin sectioned, and stained with H\&E. The tissues of an uninfected guinea pig (I, $\mathbf{J}$, and $\mathbf{K}$ ) were compared with those of the animal that died of s.c. Y. pestis CAC1 challenge (asterisk in Figure 4B). The white boxes in panels $\mathbf{C}, \mathbf{D}$, and $\mathbf{E}$ identify the areas of enlargement in panels $\mathbf{F}, \mathbf{G}$, and $\mathbf{H}$. Arrows denote bacterial microcolonies. Original magnification: $\times 200(\mathbf{C}-\mathbf{E}) ; \times 400(\mathbf{F}-\mathbf{K})$.

hemorrhage and necrotic areas with bacterial colonies (Figure 5, E and $\mathrm{H}$ ). These observations are consistent with signs of bubonic plague in the guinea pig that died of $Y$. pestis CAC1 challenge and with secondary pneumonic plague.

\section{Y. pestis CAC1 and Lack of $F 1^{+}$Reversion}

Yersinia pestis CAC1 carries an IS1541 element in the caf1A gene. ${ }^{39}$ Because IS elements are small mobile genetic elements, we entertained the possibility that CAC1 variants may revert to an $\mathrm{F}^{+}$phenotype under conditions when $\mathrm{F} 1$ is required for virulence, as occurs in the guinea pig bubonic plague model. All but one guinea pig infected by s.c. injection with $Y$. pestis CAC1 survived the infection (Figure 4B). We asked whether this guinea pig was infected with the CAC1 parent or with $\mathrm{F} 1^{+}$revertants. After necropsy, bacteria were isolated from various tissues (lymph nodes, spleen, liver, and lung) and were examined for the presence or absence of IS1541 in caf1A (Figure 5, A and B). The PCR amplification of caf1A revealed that replicating plague bacteria harbored the IS1541 insertion in caf1A (Figure 5A). When assayed for F1 expression, pilin subunits were detected in culture supernatants of $Y$. pestis CO92 but not in culture supernatants of CAC1 (Figure 5B). These findings are in agreement with the conjecture that the IS1541 element had not been removed from caf1A. Together, these results suggest that although $\mathrm{F}_{1}^{-}$strains are attenuated for virulence after s.c. injection into guinea pigs, sporadic plague disease can occur in susceptible individuals.

\section{Vaccine Protection Against Pneumonic Plague}

Guinea pigs (cohorts of eight animals) were immunized with recombinant vaccine subunits, rLcrV, rF1, and rV10, a variant of LcrV that lacks the immunosuppressive properties of this molecule. ${ }^{41}$ Recombinant proteins (50 $\mu \mathrm{g}$ absorbed to $25 \%$ Alhydrogel) were injected i.m. on days 0 and 21 . On day 42, blood was collected from two guinea pigs per group, and sera were subjected to ELISA for antibody titer determination. Each subunit vaccine raised significant antibody levels (Figure 6A). Guinea pigs were challenged by intranasal instillation of 250,000 CFU (250 MLD) of Y. pestis C092. As expected, all the mock-immunized animals died of infection within 4 days (Figure 6B). In contrast, seven of eight guinea pigs $(87.5 \%)$ immunized with the rV10 plague vaccine survived infection ( $P=0.0006$ ) (Figure 6B). Only 50\% and $12.5 \%$ of guinea pigs survived pneumonic plague challenge when immunized with rLcrV and $\mathrm{rF1}$, respectively (Figure 6B). Serum (200 $\mu \mathrm{L}$ ) from immunized guinea pigs was passively transferred into the peritoneal cavity of naive mice, which were challenged after 1 hour by s.c. injection with $20 \mathrm{MLD}$ (20 CFU) of Y. pestis strains CO92 and CAC1 (Table 1). As expected, mice that received sera from mockimmunized guinea pigs died of bubonic plague with either CO92 or CAC1 (Table 1). All the mice that received rV10specific sera survived $(P=0.003)$, regardless of the challenge strain (Table 1). Mice passively immunized with rLcrVor rF1-specific sera were partially protected against plague challenge with Y. pestis CO92. The rF1 serum did not generate protection against the CAC1 strain, whereas passive transfer of rLcrV serum afforded partial protection against a challenge with the F1 mutant (Table 1). 
A

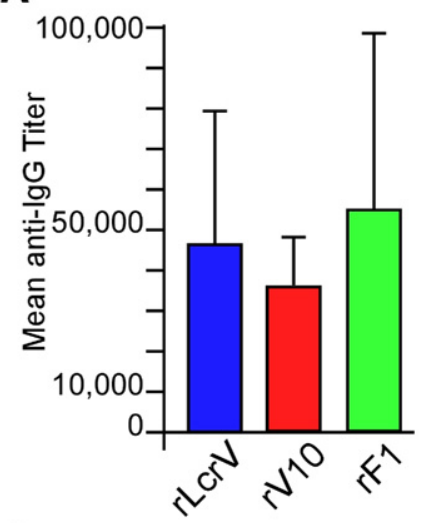

B

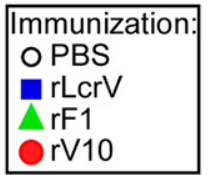

C

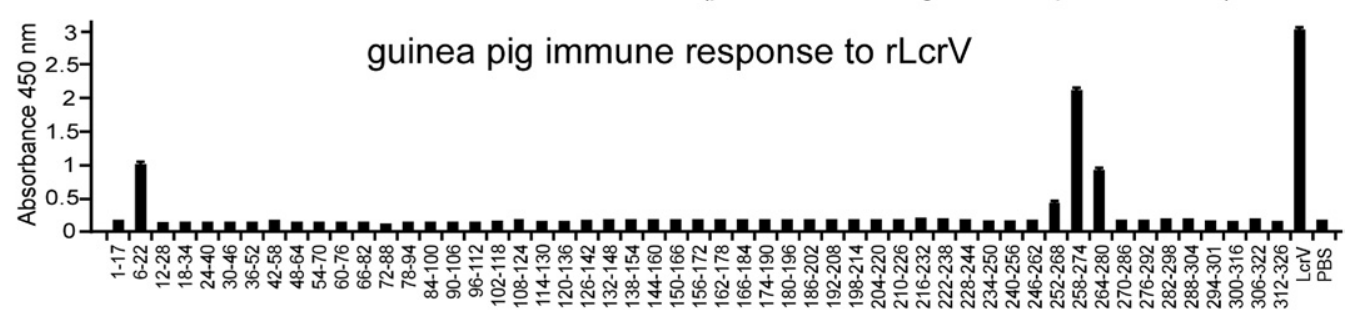

D

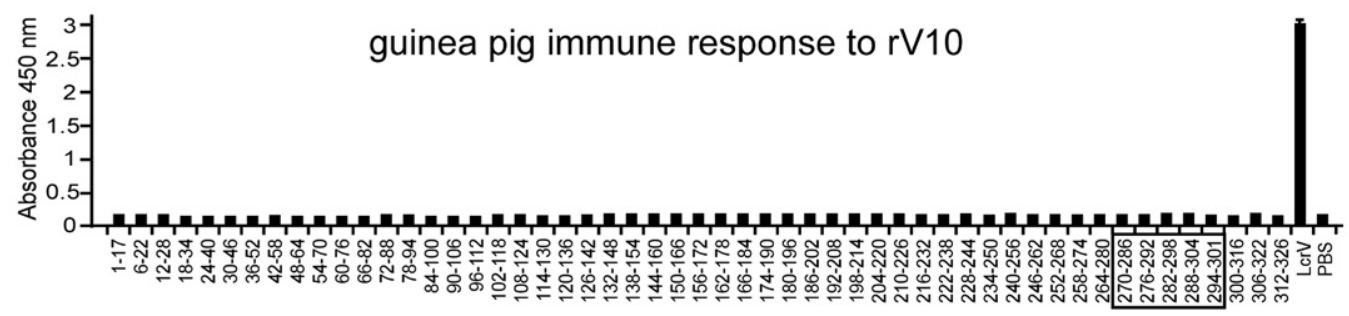

Figure 6. LcrV and V10 plague vaccines confer protection against pneumonic plague in guinea pigs. Hartley guinea pigs (cohorts of eight animals) were immunized by i.m. injection with $50 \mu \mathrm{g}$ of $\mathrm{rV} 10$, rLcrV, or $\mathrm{rF} 1$ adsorbed to $25 \%$ Alhydrogel. Immunization occurred on days 0 and 21 . A: Antibody responses to the three subunit vaccines were determined by ELISA. B: Mock-immunized (PBS) and rLcrV-, rF1-, and rV10-vaccinated guinea pigs (cohorts of eight animals) were challenged 42 days after the first vaccine administration via intranasal (i.n.) instillation of 250 MLD of $Y$. pestis CO92 (250,000 CFU). Animals were monitored for disease progression and survival for 14 days. Specific antibody responses were compared in guinea pigs immunized with rLcrV (C) and rV10 (D) using immune reactivity to overlapping 15- to 17-mer peptides spanning the full LcrV antigen via ELISA measurements. The box indicates amino acid residues that were deleted during the construction of rV10.

We wondered whether rV10-derived antibodies recognize different epitopes than do antibodies raised in response to $\mathrm{LLcrV}$ immunization. An array of $53 \mathrm{LcrV}$ peptides, ranging in size from 15 to 17 residues, with 11 or 12 amino acid overlaps, was examined for antibody reactivity by ELISA (Figure 6, C and D). Antibodies of guinea pigs immunized with rLcrV recognized four peptides: residues 6 to 22 and the three overlapping peptides (252-268, 258-274,

Table 1. Passive Immunization with Guinea Pig Immune Serum

\begin{tabular}{ccccc}
\hline & \multicolumn{4}{c}{$\begin{array}{c}\text { Animals, no. with 14-day survival/total } \\
\text { no. challenged }\end{array}$} \\
\cline { 2 - 5 } $\begin{array}{c}\text { Challenge } \\
\text { strain }^{*}\end{array}$ & $\begin{array}{c}\text { PBS/ } \\
\text { adjuvant }^{\dagger}\end{array}$ & rLcrV $^{+}$ & rV10 $^{\dagger}$ & $\mathrm{rF1}^{\dagger}$ \\
\hline Y. pestis CO92 & $0 / 5$ & $0 / 5$ & $5 / 5$ & $2 / 5$ \\
Y. pestis CAC1 & $0 / 5$ & $2 / 5$ & $5 / 5$ & $0 / 5$ \\
\hline
\end{tabular}

*Passively immunized BALB/c mice were challenged with 20 CFU of plague bacteria administered via s.c. injection.

${ }^{+}$Guinea pig serum $(200 \mu \mathrm{L})$, after immunization with PBS/adjuvant (mock) or recombinant purified proteins (rLcrV, rV10, or rF1), was administered via i.p. injection into mice 1 hour before plague challenge. and 264-280) (Figure 6C). On the other hand, antibodies formed in response to $\mathrm{rV} 10$ immunization did not react with the oligopeptides in the array (Figure 6D). These results are similar to what has been previously observed for humoral immune responses to rLcrV and rV10 vaccines in mice, rats, and NHPs. ${ }^{45}$ Taken together, these data suggest that rLcrV triggers the guinea pig immune system to generate antibodies that recognize short linear epitopes; however, these Igs may not confer protective immunity. In contrast, antibodies that recognize short linear epitopes are not formed after rV10 vaccination of guinea pigs, which seem to almost exclusively generate lg directed at conformational epitopes. Because LcrV and rV10 elicited high titers of LcrV-specific antibodies, we infer that antibody specificity, but not the total amount of antigen-specific lg, may be critical for protective immunity against pneumonic plague in guinea pigs.

\section{Discussion}

Guinea pigs offer considerable advantages as a model for human respiratory tract infections. As demonstrated 
earlier, the lungs and respiratory tract of guinea pigs closely resemble those of humans; in fact, of all available rodent models, guinea pigs most closely resemble the respiratory tract of primates. ${ }^{47,48}$ Guinea pigs are available in ample supply and, compared with NHPs, can be purchased and housed in a cost-efficient manner. On necropsy, the lungs of guinea pigs are of considerable size and permit assessments of gross anatomy and histopathologic analysis of lung tissue, mediastinal lymph nodes, pleural involvement, spleen, and blood dissemination. ${ }^{47}$ Finally, the overall size of guinea pigs permits telemetry applications for real-time measurements of respiration rate, temperature, heart rate, blood pressure, and gas variables to monitor disease progression.

Herein, we report the development of a guinea pig model for pneumonic plague that may be useful as a surrogate for NHP studies. When infected by intranasal instillation with $Y$. pestis CO92, guinea pigs developed pneumonic plague. Progression of this disease seemed to be dose dependent and mimicked the signs of pneumonic plague observed in humans (labored breathing, gasping, epistaxis, and rapid progression of pneumonia with a lethal outcome) ${ }^{8}$ The genetic requirement of the protective antigens of $Y$. pestis for lung disease in guinea pigs was tested with F1 mutant strains. The results suggest that the $\mathrm{F} 1$ capsule is not required for the pathogenesis of pneumonic plague in guinea pigs, similar to what has been reported for NHPs and humans. ${ }^{36,49}$ The MLD for pneumonic plague in guinea pigs (1000 CFU of $Y$. pestis CO92) after intranasal instillation is considerably lower than what has been reported for some aerosol challenge experiments. ${ }^{35}$ A likely explanation for this observation is the growth condition of cultures, as virulent $Y$. pestis strains grown at $37^{\circ} \mathrm{C}$ are more virulent for lung infections in guinea pigs than are the same strains propagated at $26^{\circ} \mathrm{C} .{ }^{44} \mathrm{We}$ conclude that guinea pigs represent an excellent animal model for the study of pneumonic plague.

Sebbane and colleagues ${ }^{50}$ reported that F1 pili contribute to the transmission of plague via flea bite; however, F1 is not essential for bubonic or pneumonic plague in mice. ${ }^{20}$ Herein, we report that $F 1$ variants, engineered or naturally acquired, are less likely to cause bubonic plague after s.c. injection into guinea pigs. Furthermore, some individuals in the guinea pig cohorts used herein were resistant to bubonic plague infection, which could present an obstacle to the statistical analysis of guinea pig experiments modeling bubonic plague, its prevention, or therapy.

Earlier work examined the ability of a combination vaccine, $\mathrm{rF} 1+\mathrm{rLcrV}$, to protect guinea pigs against bubonic plague with s.c. challenge experiments using the $Y$. pestis strain GB. ${ }^{34}$ However, these studies did not examine the effect of subunit vaccines on pneumonic plague. To examine whether guinea pigs are a suitable animal model to test vaccine efficacy for pneumonic plague under the "Animal Rule," we immunized animals with one of three subunit vaccines (rLcrV, rV10, and rF1). Although vaccinated animals generated large amounts of antigen-specific Ig, guinea pigs were not as well protected as were inbred mice ${ }^{24}$ or NHPs endowed with similar immune responses. ${ }^{45}$ The rV10 vaccine conferred protection in seven of eight animals, whereas rLcrV protected only 50\% of the animal cohort (four of eight guinea pigs). The observed difference between the two subunit vaccines was not significant $(P=0.12)$, and the question of whether rLCrV or rV10 generates equal levels of protective immunity requires additional tests with larger animal cohorts. Results of preliminary passive transfer experiments with guinea pig immune serum suggested that $\mathrm{rV} 10$ antibodies achieve an equal or perhaps even greater level of protection than do LCrV antibodies $(P=0.003)$. Because we tested only one dose for each vaccine and regimen (two injections at a 21-day interval), additional experiments need to be performed to comparatively evaluate the immune responses to rV10 and rLcrV in guinea pigs.

Similar to mice, rats, and NHPs, guinea pigs responded to LcrV immunization with high titers of antibodies that recognize linear and conformational epitopes and generate significant protection against pneumonic plague challenge. rF1 immunization also induced high titers of specific antibodies. However, unlike mice or $\mathrm{NHPs},{ }^{20,45} \mathrm{rF} 1$-specific antibodies did not generate vaccine protection against pneumonic plague challenge. Mouse polyclonal or monoclonal F1-specific antibodies interfere with $Y$. pestis type III injection of host immune cells, thereby enabling bacterial killing in blood and protective immunity. Passive transfer of guinea pig antibodies specific for F1 did not, however, generate the same result as murine antibodies. Because high titers of F1specific antibody correlate with protection against plague in mice and NHPs, these results suggest that, at least in guinea pigs, F1 antibodies lack at least some of the protective immunity attributes observed in mice or NHPs.

The results presented herein highlight the need for well-characterized animal models to examine plague vaccine efficacy under the "Animal Rule." The present data suggest that guinea pigs are a useful model for the testing of human subunit vaccines. These data further suggest that LcrV, the key virulence factor of plague bacteria, is also an important protective antigen in the guinea pig model for pneumonic plague because LcrVspecific antibodies that block type III injection into host immune cells provide protection from this disease. ${ }^{24}$ In contrast, the structural genes for $\mathrm{F} 1$ pili are dispensable for the pathogenesis of pneumonic plague in guinea pigs, and F1-specific immune responses failed to generate disease protection.

\section{Acknowledgments}

We thank members of the Schneewind laboratory for discussion, the Animal Research and Immunology Core (The University of Chicago) for assistance with BSL-3 and animal experiments, and Katie Overheim and Trevor Brasel (Lovelace Biomedical and Environmental Research Institute, Albuquerque, NM) for NHP experiments.

\section{References}

1. Yersin A: La peste bubonique à Hong-Kong. Ann Inst Pasteur 1894, $2: 428-430$ 
2. Stenseth NC, Atshabar BB, Begon M, Belmain SR, Bertherat E, Carniel E, Gage KL, Leirs H, Rahalison L: Plague: past, present, and future. PLoS Med 2008, 5:e3

3. Perry RD, Fetherston JD: Yersinia pestis: etiologic agent of plague. Clin Microbiol Rev 1997, 10:35-66

4. Davis S, Begon M, De Bruyn L, Ageyev VS, Klasovskiy NL, Pole SB, Viljugrein $\mathrm{H}$, Stenseth NC, Leirs H: Predictive thresholds for plague in Khazakhstan. Science 2004, 304:736-738

5. Simond PL: La propagation de la peste. Ann Inst Pasteur 1898, 12:625-687

6. Inglesby TV, Dennis DT, Henderson DA, Bartlett JG, Ascher MS, Eitzen E, Fine AD, Friedlander AM, Hauer J, Koerner JF, Layton M, McDade J, Osterholm MT, O'Toole T, Parker G, Perl TM, Russell PK, Schoch-Spana M, Tonat K: Plague as a biological weapon: medical and public health management. JAMA 2000, 283:2281-2290

7. Boisier P, Rahalison L, Rasolomaharo M, Ratsitorahina M, Mahafaly M, Razafimahefa M, Duplantier J-M, Ratsifasomanana L, Chanteau S: Epidemiologic features of four successive annual outbreaks of bubonic plague in Mahajanga. Madagascar. Emerg Infect Dis 2002, 8:311-316

8. Meyer K: Pneumonic plague. Bacteriol Rev 1961, 25:249-261

9. Girard JM, Wagner DM, Vogler AJ, Keys C, Allender CJ, Drickamer LC, Keim P: Differential plague-transmission dynamics determine Yersinia pestis population genetic structure on local, regional, and global scales. Proc Natl Acad Sci U S A 2004, 101:8408-8413

10. Inglesby TV, Grossman R, O'Toole T: A plague on your city: observations from TOPOFF. Clin Infect Dis 2001, 32:436-445

11. Brubaker RR: The recent emergence of plague: a process of felonious evolution. Microb Ecol 2004, 47:293-299

12. Smiley ST: Current challenges in the development of vaccines for pneumonic plague. Expert Rev Vaccines 2008, 7:209-221

13. Quenee LE, Schneewind O: Plague vaccines and the molecular basis of immunity against Yersinia pestis. Hum Vaccin 2009, 5:817-823

14. Andrews GP, Heath DG, Anderson GW Jr, Welkos SL, Friedlander AM: Fraction 1 capsular antigen (F1) purification from Yersinia pestis CO92 and from an Escherichia coli recombinant strain and efficacy against lethal plague challenge. Infect Immun 1996, 64:2180-2187

15. Baker EE, Sommer H, Foster LE, Meyer E, Meyer KF: Studies on immunization against plague, I: the isolation and characterization of the soluble antigen of Pasteurella pestis. J Immunol 1952, 68:131145

16. Burrows TW: An antigen determining virulence in Pasteurella pestis. Nature 1956, 177:426-427

17. Mueller CA, Broz P, Muller SA, Ringler P, Erne-Brand F, Sorg I, Kuhn $M$, Engel A, Cornelis GR: The V-antigen of Yersinia forms a distinct structure at the tip of injectisome needles. Science 2005, 310:674676

18. Heath DG, Anderson GW Jr, Mauro JM, Welkos SL, Andrews GP, Adamovicz JJ, Friedlander AM: Protection against experimental bubonic and pneumonic plague by a recombinant capsular F1-V antigen fusion protein vaccine. Vaccine 1998, 16:1131-1137

19. Motin VM, Nedialkov YA, Brubaker RR: V antigen-polyhistidine fusion peptide: binding to $\mathrm{LCrH}$ and active immunity against plague. Infect Immun 1996, 64:4313-4318

20. Quenee L, Cornelius CA, Ciletti NA, Elli D, Schneewind O: Yersinia pestis caf1 $(\mathrm{F} 1)$ variants and the limits of plague vaccine protection. Infect Immun 2008,76:2025-2036

21. Williamson ED, Flick-Smith HC, LeButt C, Rowland CA, Jones SM, Waters EL, Gwyther RJ, Miller J, Packer PJ, Irving M: Human immune response to a plague vaccine comprising recombinant $\mathrm{F} 1$ and $\mathrm{V}$ antigens. Infect Immun 2005, 73:3598-3608

22. Burrows TW, Bacon GA: The effect of loss of different virulence determinants on the virulence and immunogenicity of strains of Pasteurella pestis. Br J Exp Pathol 1958, 39:278-291

23. Davis KJ, Fritz DL, Pitt MLM, Welkos SL, Worsham PL, Friedlander AM: Pathology of experimental pneumonic plague produced by fraction 1-positive and fraction 1-negative Yersinia pestis in African green monkeys (Cercopitheus aethiops). Arch Pathol Lab Med 1996, 120: $156-163$

24. DeBord KL, Anderson DM, Marketon MM, Overheim KA, DePaolo RW, Ciletti NA, Jabri B, Schneewind O: Immunogenicity and protective immunity against bubonic and pneumonic plague by immunization of mice with the recombinant V10 antigen, a variant of LcrV. Infect Immun 2006, 74:4910-4914
25. Sebbane F, Gardner D, Long D, Gowen BB, Hinnebusch BJ: Kinetics of disease progression and host response in a rat model of bubonic plague. Am J Pathol 2005, 166:1427-1439

26. Anderson DA, Ciletti NA, Lee H, Elli D, Segal J, DeBord KL, Overheim KA, Brubaker RR, Schneewind O: Pneumonic plague pathogenesis and immunity in brown Norway rats. Am J Pathol 2009, 174:910-921

27. Van Andel R, Sherwood R, Gennings C, Lyons CR, Hutt J, Gigliotti A, Barr E: Clinical and pathological features of cynomologus macaques (Macaca fascicularis) infected with aerosolized Yersinia pestis. Comp Med 2008, 58:68-75

28. Meyer KF, Smith G, Foster L, Brookman M, Sung MH: Live, attenuated Yersinia pestis vaccine: virulent in non-human primates, harmless to guinea pigs. J Infect Dis 1974, 129:S85-S112

29. Fukui GM, Lawton WD, Janssen WA, Surgalla MJ: Response of guinea pig lungs to in vivo and in vitro cultures of Pasteurella pestis. $\mathrm{J}$ Infect Dis 1957, 100:103-107

30. Donovan JE, Ham D, Fuki EM, Surgalla MJ: Role of the capsule of Pasteurella pestis in bubonic plague in the guinea pig. $\mathrm{J}$ Infect Dis 1961, 109:154-157

31. Girard G: Plague. Annu Rev Microbiol 1955, 9:253-277

32. Feodorova VA, Pan'kina LN, Savostina EP, Sayapina LV, Motin VL, Dentovskaya SV, Shaikhutdinova RZ, Ivanov SA, Lindner B, Kondakova AN, Bystrova OV, Kocharova NA, Senchenkova SN, Holst O, Pier GB, Knirel YA, Anisimov AP: A Yersinia pestis IpxM-mutant live vaccine induces enhanced immunity against bubonic plague in mice and guinea pigs. Vaccine 2007, 25:7620-7628

33. von Metz E, Eisler DM, Hottle GA: Immunogenicity of plague vaccines in mice and guinea pigs. Appl Microbiol 1971, 22:84-88

34. Jones SM, Griffin KF. Hodgson I, Williamson ED: Protective efficacy of a fully recombinant plague vaccine in the guinea pig. Vaccine 2003 , 21:3912-3918

35. Santi L, Giritch A, Roy CJ, Marillonnet S, Klimyuk V, Gleba Y, Webb R, Arntzen CJ, Mason HS: Protection conferred by recombinant Yersinia pestis antigens produced by a rapid and highly scalable plant expression system. Proc Natl Acad Sci U S A 2006, 103:861-866

36. Friedlander AM, Welkos SL, Worsham PL, Andrews GP, Heath DG, Anderson GW Jr, Pitt LM, Estep J, Davis K: Relationship between virulence and immunity as revealed in recent studies of the F1 capsule of Yersinia pestis. Clin Infect Dis 1995, 21:S178-S181

37. Doll JM, Zeitz PS, Ettestad P, Bucholtz AL, Davis T, Gage KL: Cattransmitted fatal pneumonic plague in a person who traveled from Colorado to Arizona. Am J Trop Med Hyg 1994, 51:109-114

38. Parkhill J, Wren BW, Thompson NR, Titball RW, Holden MT, Prentice MB, Sebaihia M, James KD, Churcher C, Mungall KL, Baker S, Dasham D, Bentley SD, Brokks K, Cerdeno-Tarraga AM, Chillingworth T, Cronin A, Davies RM, Davis P, Dougan G, Feltwell T, Hamlin N, Holroyd S, Jagels K, Karlyshev AV, Leather S, Moule S, Oyston PC, Quail M, Rutherford K, Simmonds M, Skelton J, Stevens K, Whitehead S, Barrell BG: Genome sequence of Yersinia pestis, the causative agent of plague. Nature 2001, 413:523-527

39. Cornelius CA, Quenee LE, Elli D, Ciletti NA, Schneewind O: Yersinia pestis IS1541 transposition provides for escape from plague immunity. Infect Immun 2009, 77:1807-1816

40. Studier FW, Rosenberg AH, Dunn JJ, Dubendorff JW: Use of T7 polymerase to direct expression of cloned genes. Methods Enzymol 1990, 185:60-89

41. Overheim KA, Depaolo RW, Debord KL, Morrin EM, Anderson DM, Green NM, Brubaker RR, Jabri B, Schneewind O: LcrV plague vaccine with altered immunomodulatory properties. Infect Immun 2005 , 73:5152-5159

42. Deng W, Burland V, Plunkett G III, Boutin A, Mayhew GF, Liss P Perna NT, Rose DJ, Mau B, Zhou S, Schwartz DC, Fetherston JD, Lindler LE, Brubaker RR, Plano GV, Straley SC, McDonough KA, Nilles ML, Matson JS, Blattner FR, Perry RD: Genome sequence of Yersinia pestis KIM. J Bacteriol 2002, 184:4601-4611

43. Aida $Y$, Pabst MJ: Removal of endotoxin from protein solutions by phase separation using Triton X-114. J Immunol Methods 1990, 132: 191-195

44. Samoilova SV, Samoilova LV, Yezhov IN, Drozdov IG, Anisimov AP. Virulence of pPst+ and pPst- strains of Yersinia pestis for guineapigs. J Med Microbiol 1996, 45:440-444

45. Cornelius CA, Quenee LE, Elli D, Ciletti NA, Schneewind O: V10 subunit vaccine protects cynomolgus macaques from lethal pneumonic plague. Infect Immun 2008, 76:5588-5597 
46. Reed LJ, Muench $\mathrm{H}$ : A simple method of estimating fifty per cent endpoints. Am J Hyg 1938, 27:493-497

47. Meyer KF, Quan SF, Larson A: Prophylactic immunization and specific therapy of experimental pneumonic plague. Am Rev Tuberc 1948, 57:312-321

48. Gupta UD, Katoch VM: Animal models of tuberculosis for vaccine development. Indian J Med Res 2009, 129:11-18
49. Winter CC, Cherry WB, Moody MD: An unusual strain of Pasteurella pestis isolated from a fatal case of human plague. Bull WHO 1960, 23:408-409

50. Sebbane F, Jarrett C, Gardner D, Long D, Hinnebusch BJ: The Yersinia pestis caf1M1A1 fimbrial capsule operon promotes transmission by flea bite in a mouse model of bubonic plague. Infect Immun 2009, 77:1222-1229 